\title{
Medical students' attitudes to caring for a young infant - can parenting a doll influence these beliefs?
}

\author{
L E Bath, S Cunningham, N McIntosh
}

\begin{abstract}
Aim-To investigate whether attitudes to parenting were altered in final year medical students following a period spent caring for a simulated infant.

Methods-Seventy medical students during their paediatric attachment in the final year completed a questionnaire regarding personal childcare attitudes. Students attached to a teaching hospital were allocated a 24 hour time period to care for "Baby Think It Over" (BTIO), a computerised doll that simulates a 6 week old infant and records care given. The students then completed a second questionnaire assessing the impact of the experience.

Results-Forty nine per cent of students thought their advice regarding sick children was less valid than if they had their own children; $96 \%$ of students believed their approach to parents caring for young infants could be improved by caring for a
\end{abstract}

Accepted 21 September 2000

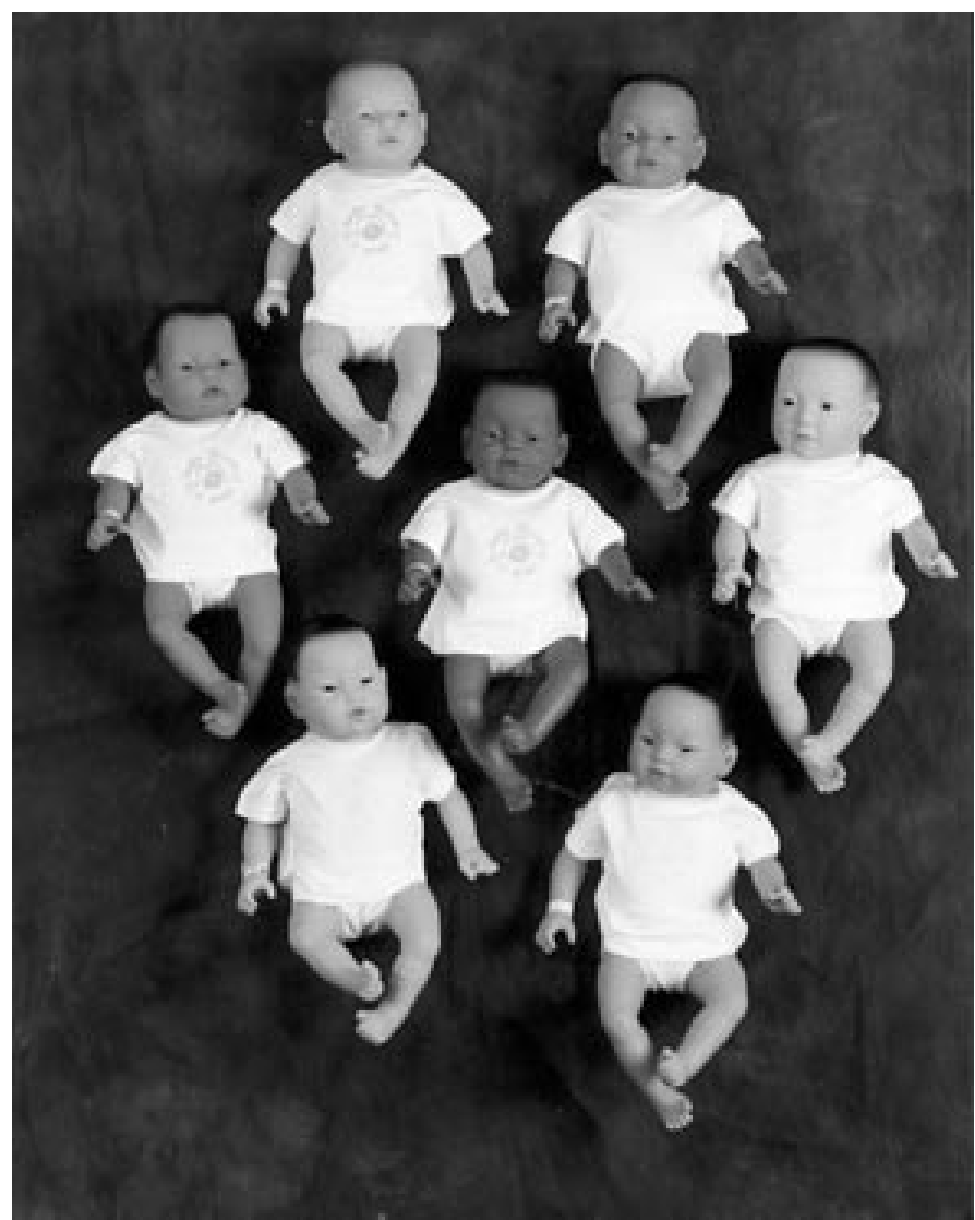

Figure 1 Baby Think It Over-group of standard babies.
6 week old infant. All the students felt their lifestyle would be affected. Following the BTIO care period, $79 \%$ considered the experience straightforward, with $35 \%$ expressing a little more empathy and $15 \%$ a lot more empathy for parents as a result. Thoughts regarding impact on lifestyle were unaltered. Caring for BTIO, however, was not considered to be a realistic experience and overall not particularly useful.

Conclusion-Simulated infants are of only limited value in increasing medical student understanding of parental concerns. (Arch Dis Child 2000;83:521-523)

Keywords: medical student; parenting; communication skills

The majority of final year medical students attending UK universities are aged 21-25 years, do not have children of their own, and have little experience of caring for newborn infants. This could be perceived as a disadvantage for students when addressing parents who have concerns about their young infants. We wished to determine the attitudes of students towards childcare, and whether an insight into the time and emotional demands of caring for a young baby would influence their attitudes and understanding. "Baby think it over" (BTIO) is a computerised doll that simulates a 6 week old infant (figs 1 and 2). The doll has been designed to assess and potentially modify teenage pregnancy attitudes, in an attempt to reduce teen pregnancy rates. In one study few equated doll care with mothering and thus the efficacy of BTIO alone as a teenage pregnancy prevention intervention was doubtful. ${ }^{1}$ We assessed the attitudes of paediatric medical students to childcare and parenting before and after caring for BTIO, to determine whether such dolls might make a valid contribution to undergraduate paediatric education.

\section{Methods}

Medical students attend an eight week attachment in paediatrics. One block of final year Edinburgh medical students $(\mathrm{n}=70)$ completed a questionnaire regarding personal experience of childcare, personal aspirations of child rearing, how personal experience may affect the interaction with parents of ill children, and potential lifestyle changes they associated with child rearing. The students attached to the central teaching hospital ( $n=34$ ) were then allocated a 24 hour time slot to care for a $10 \mathrm{lb}$ life like, computerised doll that demands attention randomly and can only be quietened by inserting a key, which is 


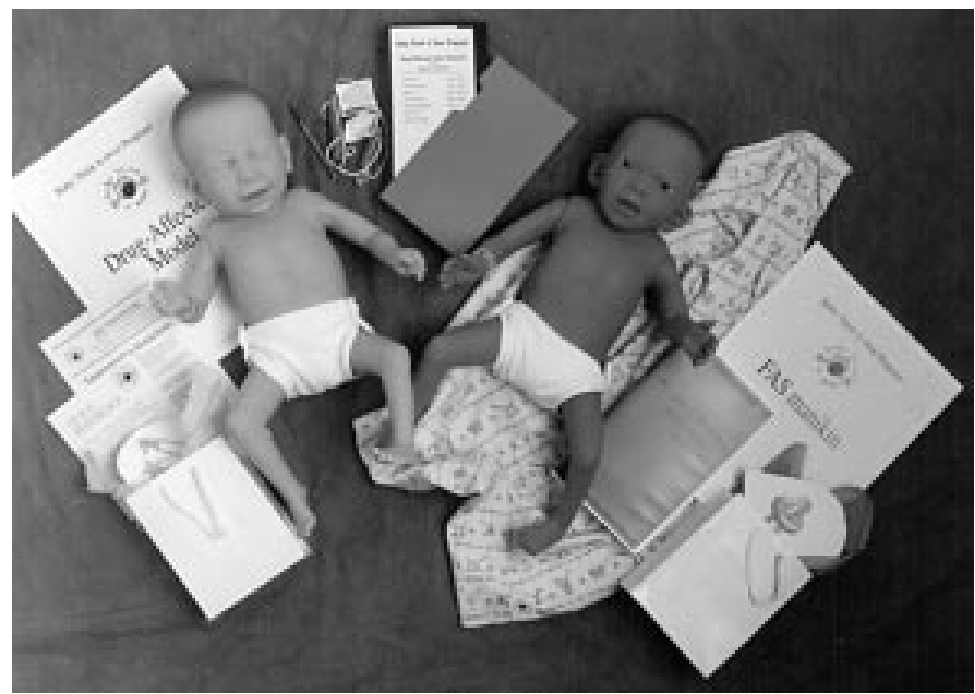

Figure 2 Baby Think It Over—drug affected baby and fetal alcohol syndrome baby.

attached to the "parent" by a tamper proof bracelet. The behaviour of the doll could be chosen from easy, normal, or cranky behaviour: as students would only be caring for the infant for a short period ( 24 hours), the doll was set to always behave in cranky mode. The doll has a computer memory that can be downloaded after the care period. The memory records the total length of time of the care episode, the number of rough handling episodes, the number of neglect events lasting longer than one minute, the number of times the head was not properly supported, and the total length of time the baby was left to cry, including crying generated by improper positioning, neglect, and head support events greater than 60 seconds. The information from each student's care period was downloaded. They completed a second questionnaire at the end of the care period, reviewing the experience and assessing whether this exposure changed their personal opinions of childcare and their attitudes towards parents of young children. The students recorded whether it was a useful or realistic experience and were asked to give an honest appraisal of their parenting skills over the 24 hours on a $5 \mathrm{~cm}$ visual analogue scale, where 0 was a negative response and 5 was a very positive response.

\section{Results}

BASELINE FEELINGS

Seventy students aged 22.6 years (SD 2.3) answered the initial questionnaire. Eighty nine per cent had siblings and one had her own children; $51 \%$ had cared for a child less than 4 years of age for a minimum of six continuous hours, at some time in the previous five years. We asked the students with no children how they thought advice from them should be taken by parents with sick children: $49 \%$ considered that their advice regarding sick children was less valid than if they had their own children, $49 \%$ thought their advice was just as valid, and $2 \%$ felt their advice was more valid. Ninety six per cent of students believed their approach to parents caring for young infants could be improved by caring for a 6 week old infant. The task of caring for a young infant was expected to be tiring $(96 \%)$. Confidence regarding the practicalities of childcare varied from straightforward $(26 \%)$ to very difficult $(11 \%)$, though the majority were unsure $(63 \%)$. All the students felt their lifestyle would be affected- $49 \%$ expecting to stay at home at least six nights out of seven, and $49 \%$ expecting to go out socially rarely (less than once per month). Of the 69 students without children, $96 \%$ wished to have children within the next 2-15 years (median 10 years), 3\% were undecided, and $1 \%$ did not wish to have children. They thought that the most rewarding aspect of having their own children would be the feeling of being a complete person or family $(86 \%) ; 13 \%$ of students were keen to pass part of themselves onto future generations; and one student wanted someone available to help when he was old! The most daunting aspect of childcare was the worry that they would not know what to do, followed by change in social circumstances, then fear of hurting them. The least daunting was the financial burden.

\section{PERCEPTIONS AFTER CARING FOR BTIO}

Thirty four students who were attached to the central teaching hospital cared for BTIO; $79 \%$ found that caring for the baby was straightforward the majority of the time, $15 \%$ found it easy all the time, and $6 \%$ were unsure most of the time. Caring for BTIO was significantly easier than students had perceived infant care to be at the start of the study $(p<0.01$, Wilcoxon signed ranks test). Estimates of the tiredness that would be experienced when caring for a young baby were not significantly altered from baseline by BTIO: $64 \%$ found caring for BTIO tiring-mentally $32 \%$ and physically $90 \%$ (the majority finding BTIO heavy to carry around in her car seat). Loss of personal freedom and being woken at night were considered moderate problems; not knowing why BTIO cried was a minor problem. After caring for BTIO, 47\% felt their professional approach to the parents of young children was unchanged, 35\% felt a little more empathy, and $15 \%$ felt a lot more empathy; $3 \%$ felt less empathy for worried parents. Their decisions regarding their own timing of child rearing were unaffected by caring for BTIO. Thoughts regarding impact on lifestyle and nights out were also unaltered.

\section{ATTITUDES TOWARDS BTIO}

The median response (and interquartile range (IQR)) on a scale of $0-5$ ( 0 equating to not at all and 5 as very useful) as to whether the students thought it was a useful experience was 2.0 (IQR 1-3). The median response to whether it was a realistic experience was 1 (IQR 0.5-2). Students were also asked to give an honest appraisal of how good they considered their parenting skills to have been over the 24 hours: on a scale of $0-5$, where 0 represented no parenting skills at all, up to 5 (skills couldn't have been better). The median response from students was 1.5 (0.5-3.4). This estimate was correlated with the student's actual score downloaded on the baby's compu- 
Table 1 Care scores per student from data downloaded from BTIO doll at end of care period

\begin{tabular}{lllll}
\hline $\begin{array}{l}\text { Total care period } \\
(h)\end{array}$ & $\begin{array}{l}\text { No. episodes poor } \\
\text { head control }\end{array}$ & $\begin{array}{l}\text { No. episodes rough } \\
\text { handling }\end{array}$ & $\begin{array}{l}\text { No. of neglect } \\
\text { events }\end{array}$ & Total minutes cried \\
\hline $22.7(3.3)$ & $6.5(6.6)$ & $0.4(1.0)$ & $1.1(1.2)$ & $8.9(7.3)$ \\
\hline
\end{tabular}

Results expressed as mean (SD).

ter (table 1). Actual quality of care was scored by adding all events in the time period divided by the length of time of childcare. There was a significant correlation between actual childcare as downloaded from the computer and reported childcare $(r=0.342, \mathrm{p}<0.02$, Spearman's rank correlation coefficient).

\section{Discussion}

This study assessed whether a simulated doll could help develop the compassionate paediatric skills of final year medical students who usually have no experience of the intensity of the demands of a young baby. Before starting the study the majority of students believed that their approach to parents, who were caring for young infants, could be improved by caring for a 6 week old infant, and many students lacked confidence about the validity of their advice to parents. The doll provided to them for 24 hours simulated a 6 week old infant, and did develop an increased empathy towards parents in half the students. Although the majority of students initially felt unsure about having to care for a baby, they found the practical caring for BTIO straightforward. The students carried the doll around with them on the wards and thus their daytime activities were not restricted. Some also commented that they enjoyed the interest they received from many parents when demonstrating the merits of BTIO.
Medical students are expected to gain significant knowledge in many subject areas in a very short period of time. Paediatric knowledge is particularly difficult to assimilate in a short time frame, as it often lies outside the general education remit of the early years at medical school. In the past few years many medical schools have recognised this, and have sought to have students concentrate on a core paediatric curriculum, ${ }^{2}$ with greater weight given to communication skills with parents. Communicating with parents, as a skill, is one of the most difficult for medical students to achieve (that is, taking a history from someone that is not the patient). Our use of a simulated infant was an attempt to improve understanding of the relationship between parent and child in order to develop those skills. Students however, did not consider the experience useful or realistic. The use of the doll appears to be of limited value in helping students to develop an understanding of parenting skills during their undergraduate paediatric attachment. We are considering the future for our BTIO. Although our medical students were not appreciative of her qualities we are hoping to find BTIO a good home in the community.

The authors would like to thank Elaine Forbes and Lisa Horsburgh for their assistance in downloading the information.

1 Kralewski J, Stevens-Simon C. Does mothering a doll change teens' thoughts about pregnancy. Pediatrics 2000;105:E30.

2 Haddad D, Robertson KJ, Cockburn F, Helms P, McIntosh $\mathrm{N}$, Olver RE. What is core? Guidelines for the core curriculum in paediatrics. Med Educ 1997;31:354-8. 